
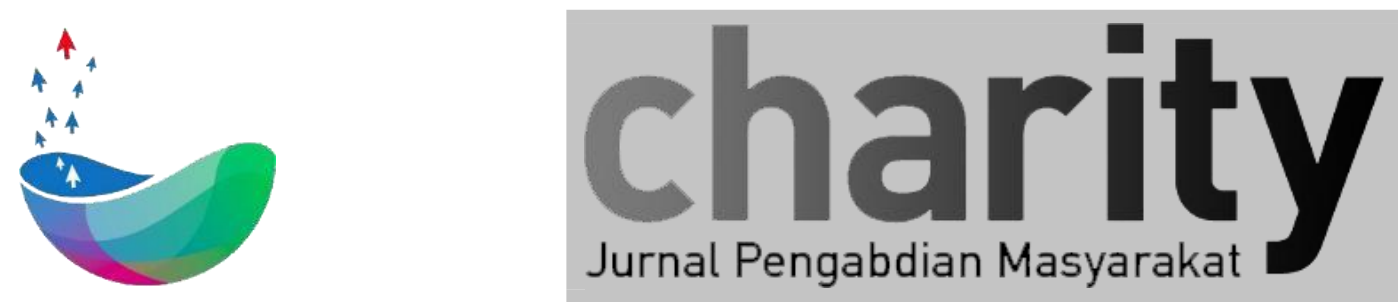

\title{
Penerapan Aplikasi Pembelajaran Berbasis Multimedia untuk Menunjang Proses Belajar Mengajar di SD Negeri Kertasari 01 Kabupaten Bandung
}

\author{
Dede Tarwidi*, Putu Harry Gunawan, Didit Adytia \\ School of Computing, Telkom University \\ *dedetarwidi@telkomuniversity.ac.id
}

\section{INFO ARTIKEL}

Diterima 29 November 2019

Direvisi 30 Juni 2020

Disetujui 27 Agustus 2002

Tersedia Online 28 Agustus

2020

Keyword: interaktif, pembelajaran, materi ajar, t-test.

\begin{abstract}
ABSTRAK
Makalah ini menyajikan penerapan aplikasi pembelajaran interaktif berbasis multimedia untuk menunjang proses pelajar pengajar di SD Negeri Kertasari 01 Kabupaten Bandung. Penerapan aplikasi pembelajaran ini dituangkan kedalam sebuah pelatihan pembuatan konten pembelajaran interaktif dengan multimedia. Masyarakat sasar yang dijadikan sebagai mitra adalah guru-guru SD Negeri Kertasari 01 Desa Tarumajaya Kecamatan Kertasari Kabupaten Bandung yang jaraknya sekitar $42 \mathrm{~km}$ dari Telkom University. Permasalahan yang dihadapi oleh masyarakat sasar adalah kurangnya media interaktif yang menunjang proses belajar mengajar, dalam satu kelas jumlah siswa terlalu banyak, proses penyampaian materi masih menggunakan papan tulis, siswa masih menggunakan buku ajar yang konvensional, keterbatasan waktu belajar siswa di sekolah. Untuk mengatasi permasalahan-permasalahan tersebut, salah satu solusinya adalah dengan pembuatan materi ajar interaktif berbasis teknologi multimedia. Hal inilah yang mendorong kami untuk memberikan pelatihan bagi para guru SD Negeri Kertasari 01 dalam pembuatan materi ajar dengan bantuan multimedia. Untuk mengukur apakah pelatihan ini memberikan pengaruh signifikan terhadap kemampuan peserta pelatihan dalam membuat materi ajar berbasis multimedia, kami melakukan observasi kemampuan peserta sebelum dan sesudah pelatihan. Hasil observasi kemudian dianalisis menggunakan t-test. Hasil dari analisis menunjukkan terdapat cukup bukti dengan tingkat kesalahan 5\% bahwa ada perubahan yang signifikan dalam pelatihan pembuatan konten pembelajaran interaktif berbasis multimedia.
\end{abstract}

Korespondensi:

School of Computing, Telkom University

Jl. Telekomunikasi No. 1, Terusan Buah Batu, Bandung, 40257, Indonesia

E-mail : dedetarwidi@telkomuniversity.ac.id

ORCID ID:

Penulis Pertama: orcid.org/0000-0002-9087-7361

https://doi.org/xxx 
Paper_reg_number xxx @ T The Authors. Published by Directorate of Research and Community Service, Telkom University.

This is an open access article under the xxx license (https://creativecommons.org/licenses/xxx)

\section{Pendahuluan}

Sudah menjadi rahasia umum jika mutu pendidikan sekolah dasar yang berada di daerah perdesaan lebih rendah jika dibandingkan sekolah yang berada di daerah perkotaan. Ada beberapa faktor yang menyebabkan mutu Pendidikan di perdesaan rendah, salah satu yang utama adalah sarana dan prasarana penunjang proses belajar mengajar di sekolah yang masih terbatas. Selain itu, kualitas penyampaian materi ajar dari tenaga pendidik ke siswa sekolah dasar di perdesaan masih kalah jauh jika dibandingkan dengan di perkotaan. Beberapa faktor lainnya yang menyebabkan mutu Pendidikan di daerah perdesaan yang masih rendah adalah

- Cara belajar yang kurang efektif

- Waktu belajar di sekolah yang terbatas

- Bahan ajar yang terbatas

- Keterbatasan informasi

Dengan semakin berkembangnya teknologi digital, maka penggunaan teknologi dalam bidang Pendidikan berkembang begitu cepat. Saat ini teknologi multimedia sudah mulai digunakan dalam proses belajar mengajar di sekolah dasar. Dengan teknologi multimedia, proses belajar mengajar di kelas dapat berjalan lebih efektif. Selain itu, materi aja yang sudah disampaikan di sekolah dapat diulang kembali oleh siswa di rumah.

Pembelajaran berbasis multimedia adalah pembelajaran yang menggunakan teknologi multimedia yaitu penggabungan dari media teks, gambar, animasi, audio, dan video. Pembelajaran dengan multimedia akan lebih efektif jika dibandingkan dengan pembelajaran konvensional (tatap muka langsung) karena siswa dapat melihat, mendengar, dan mempraktikan saat itu juga. Diharapkan dengan penerapan aplikasi berbasis multimedia dapat membantu para guru dalam penyampaian materi ajar sehingga proses belajar mengajar di kelas dapat berjalan lebih efektif [1-4].

Masyarakat sasar dalam pengabdian masyarakat ini adalah guru-guru di SD Negeri Kertasari 01 Kabupaten Bandung. Sekolah ini berdiri sejak tahun 1962 dan sejak tahun 2015 memiliki akreditasi B. Dari Telkom University, sekolah SDN Kertasari 01 memiliki jarak sekitar $42 \mathrm{~km}$ dengan jarak tempuh sekitar 2 jam. Lokasi sekolah ini berada dekat dengan Situ Cisanti yang merupakan hulu dari sungai Citarum. Gambar 1 menunjukkan foto keadaan dari SD Negeri Kertasari 01 Kabupaten Bandung. Berikut profil lengkap SD Negeri Kertasari 01. Pengabdian masyarakat di hulu maupun hilir sungai Citarum telah banyak dilakukan [5].

Nama : SDN KERTASARI 01

NPSN 20205487

Alamat : Kp Kertasari, Desa Tarumajaya , Kec. Kertasari, Kabupaten Bandung 40386

Email : sdnkertasarisatu@gmail.com 


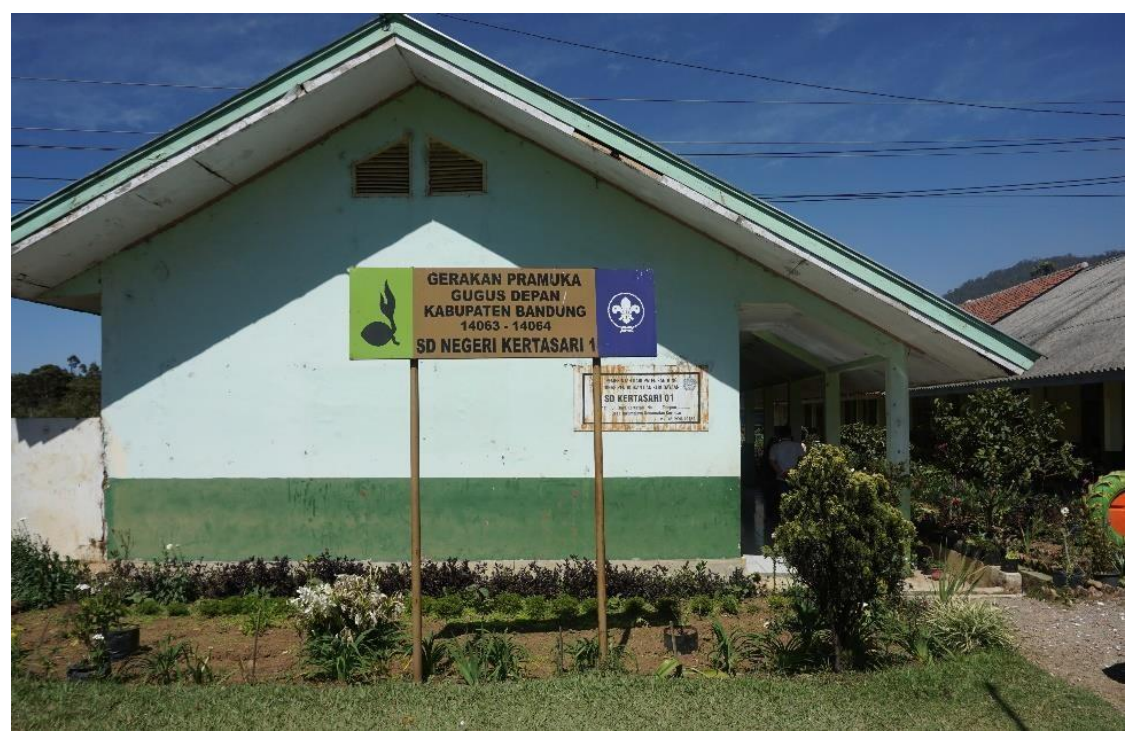

Gambar 1. Foto SD Negeri Kertsari 01 Kabupaten Bandung

Para guru di SD Negeri Kertasari 01 Kabupaten Bandung membutuhkan adanya perubahan dalam proses belajar mengajar di sekolah yang mengikuti perkembangan teknologi Pendidikan saat ini. Salah satu teknologi yang dibutuhkan adalah teknologi multimedia. Dengan penerapan aplikasi multimedia untuk menunjang pembelajaran di sekolah diharapkan dapat meningkatkan mutu Pendidikan di daerah perdesaan.

\section{Metodologi}

Tahapan-tahapan dalam pelaksanaan pengabdian masyarakat ini dapat diuraikan sebagai berikut.

1. Persiapan contoh materi ajar sekolah dasar. Contoh materi yang akan dijadikan bahan pembuatan konten materi ajar dengan multimedia akan disediakan oleh guru di SD Negeri Kertasari 01.

2. Persiapan konten multimedia. Konten multimedia yang mendukung materi ajar yang diberikan oleh para guru akan disiapkan oleh Tim Dosen.

3. Pembuatan konten materi ajar dengan multimedia. Pembuatan konten materi pembelajaran berbasis multimedia akan disiapkan oleh Tim Dosen.

4. Pembuatan modul pelatihan. Untuk memudahkan penyampaian materi pelatihan dalam pembuatan konten materi ajar dengan multimedia maka akan dibuatkan modul pelatihan.

5. Pelatihan penerapan aplikasi berbasis multimedia. Penyelenggaraan pelatihan pembuatan konten materi ajar dengan multimedia akan diisi oleh Tim Dosen.

Gambaran IPTEK yang ditransfer ke mitra dapat dilihat pada Gambar 2. 
Input: Tidak ada media yang interaktif untuk proses belajar mengajar, dalam satu kelas jumlah siswa terlalu banyak, proses penyampaian materi masih menggunakan papan tulis, masih menggunakan buku ajar yang kon?ensional, keterbatasan waktu belajar siswa di sekolah

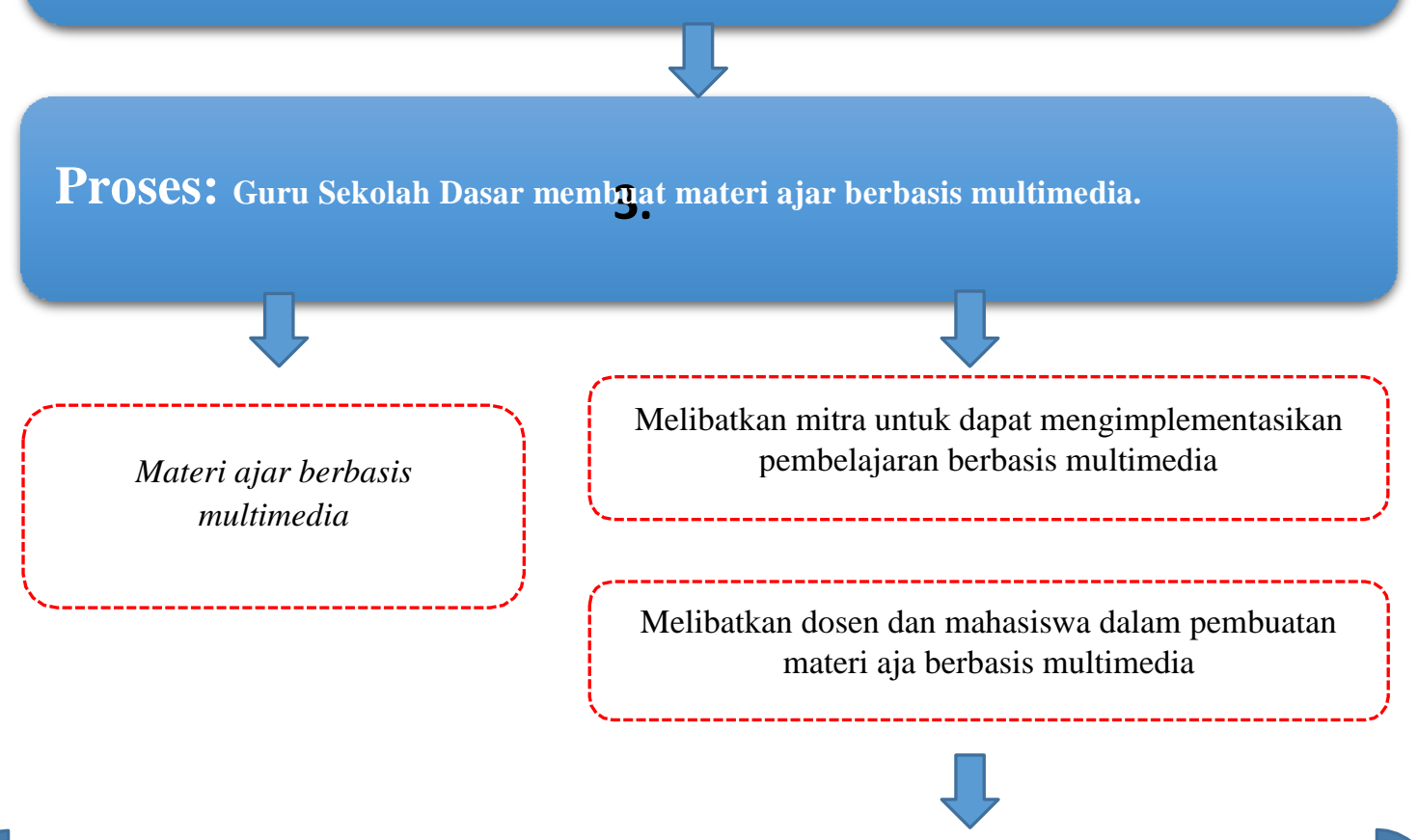

Pelatihan pembuatan materi ajar berb4is multimedia untuk para guru di SD Negeri 01 Kabupaten Bandung yang akan dilaksananakan bulan Oktober 2019

5.

\section{6utput}

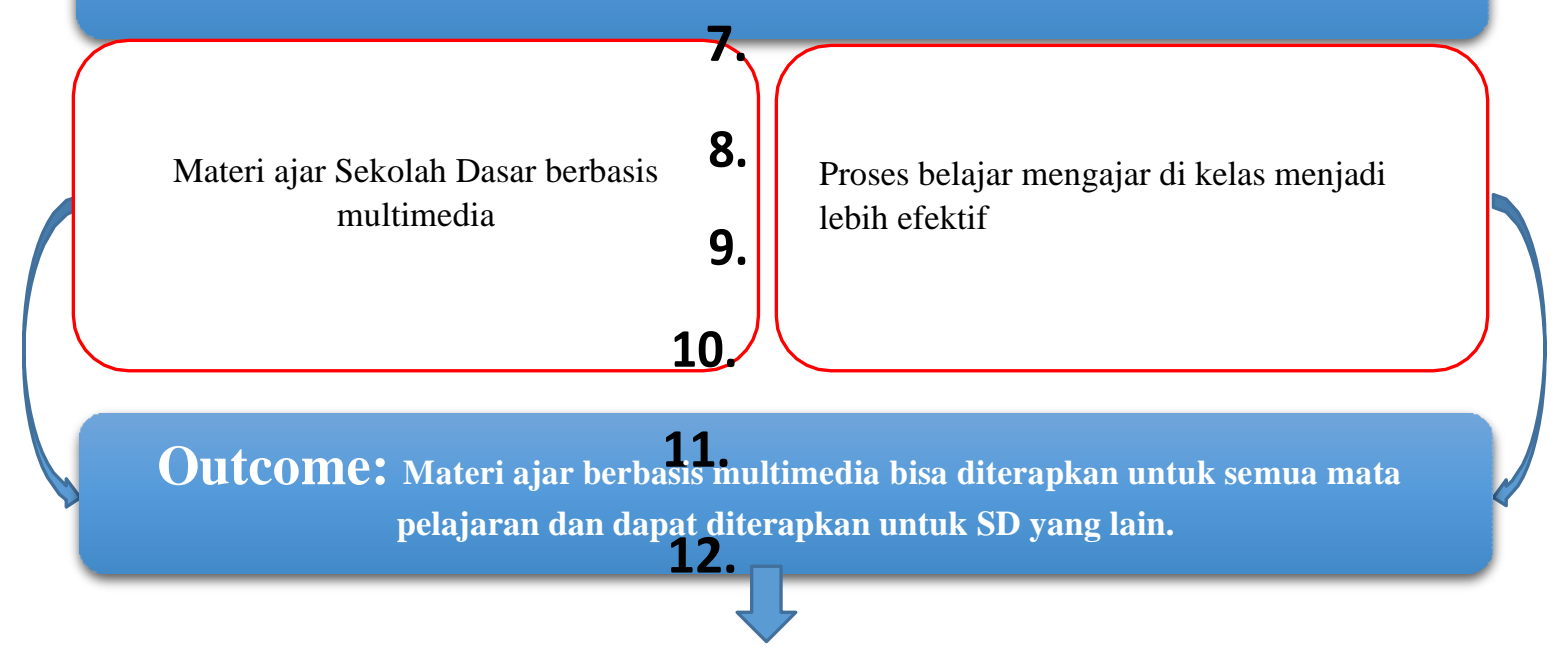

Evaluasi Pelaksanaan PkM: Evaluasi akan dilakukan dengan menggunakan kuesioner untuk memastikan pengabdian masyarakat ini sesuai sasaran.

Gambar 2. Gambaran IPTEK yang ditransfer ke mitra. 


\section{Hasil dan Diskusi}

Secara umum kegiatan pengabdian kepada masyarkat ini terdiri dari tiga kegiatan. Kegiatan pertama adalah pembuatan template pembelajaran interaktif berbasis multimedia. Dalam kegiatan ini kami membuat template silde PowerPoint interaktif menggunakan Macro. Ada dua jenis template yang dibuat, yang pertama adalah template slide interaktif untuk pengajaran dan yang kedua adalah template slide untuk quiz interaktif. Kedua template ini dibuat sedemikian sehingga para guru bisa menggunakannya dengan mudah.

Kegiatan kedua dalam pengabdian kepada masyarakat ini adalah pembuatan modul pelatihan. Pembuatan modul ini ditujukan agar Tim Dosen lebih mudah menyampaikan materi pelatihan. Selain itu, modul pelatihan bisa juga digunakan dikemudian hari oleh para guru jika suatu saat materi yang telah disampaikan sudah lupa. Dalam modul ini, dijelaskan bagaimana menuliskan script kedalam Macro agar slide bisa berfungsi interaktif.

Kegiatan ketiga adalah kegiatan inti yaitu pelatihan pembuatan materi ajar interaktif, berbasis multimedia. Pelatihan ini diikuti oleh seluruh guru SD Negeri Kertasari 01 yaitu berjumlah 7 orang. Kegiatan pelatihan dibagi menjadi dua sesi. Sesi pertama adalah pembuatan slides interaktif dengan multimedia. Dalam sesi ini, peserta pelatihan diajarkan mengedit template slide yang sudah dibuat oleh Tim Dosen. Diantaranya yang diajarkan dalam sesi ini adalah bagaimana menambahkan konten gambar, audio, dan video. Sesi kedua dalam pelatihan ini adalah pembuatan quiz interaktif menggunakan Macro. Untuk pembuatan quiz ini relatif tidak sulit karena semunya sudah dibuatkan templatenya.

Ada beberapa tantangan dalam pelaksanaan pelatihan ini. Peserta pelatihan yaitu guru-guru SD Negeri Kertasari 01, hamper semuanya tidak pernah menggunakan laptop, sehingga agak kesulitan juga dalam memperkenalkan perangkat pendukung ini. Selain itu, penggunaan PowerPoint dalam pembelajaran sangat jarang mereka gunakan. Hal ini mengakibatkan pelatihan lebih banyak dihabiskan waktunya untuk hal yang tidak berhubungan dengan materi pelatihan. Perlu diketahui, SD Negeri Kertasari 01 berada di atas gunung bersebelahan dengan Situ Cisanti yang merupakan hulu dari Sungai Citarum.

Untuk mengukur tingkat keberhasilan dari pelatihan ini dan juga mengukur tingkat kepuasan peserta/pengguna, maka peserta diminta untuk mengisi kuisioner yang telah kami sediakan. Berikut adalah pertanyaan dalam kuisioner tersebut.

1.Program pengabdian masyarakat ini sudah sesuai dengan tujuan kegiatan itu sendiri.

2. Program pengabdian kepada masyarakat isi sudah sesuai dengan kebutuhanvmasyarakat sasarnya.

3. Waktu pelaksanaan program pengabdian masyarakat ini relatif telah mencukupi sesuai kebutuhan.

4. Dosen dan mahasiswa Universitas Telkom bersikap ramah, cepat dan tanggap membantu selama kegiatan.

5. Masyarakat setempat menerima dan mengharapkan program pengabdian masyarakat Universitas Telkom saat ini dan masa yang akan datang 
Masyarakat setempat menerima dan mengharapkan program pengabdian masyarakat Universitas Telkom saat ini dan masa yang akan datang. Berikut ini adalah hasil kuisioner pengabdian kepada masyarakat penerapan aplikasi pembelajaran berbasis multimedia.

- Program pengabdian masyarakat ini sudah sesuai dengan tujuan kegiatan itu sendiri.
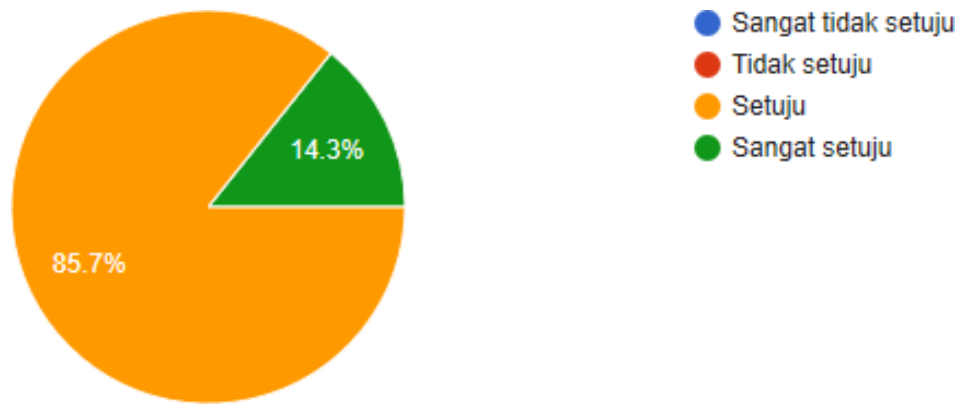

- Program pengabdian kepada masyarakat isi sudah sesuai dengan kebutuhan masyarakat sasarnya.

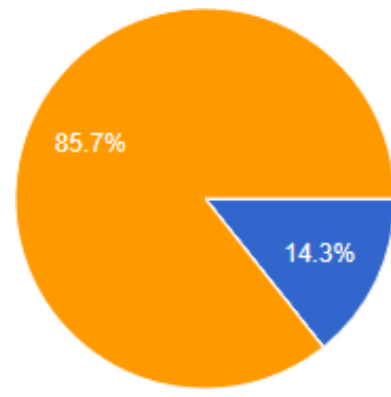

Sangat tidak setuju

Tidak setuju

Setuju

Sangat setuju

- Waktu pelaksanaan program pengabdian masyarakat ini relatif telah mencukupi sesuai kebutuhan.
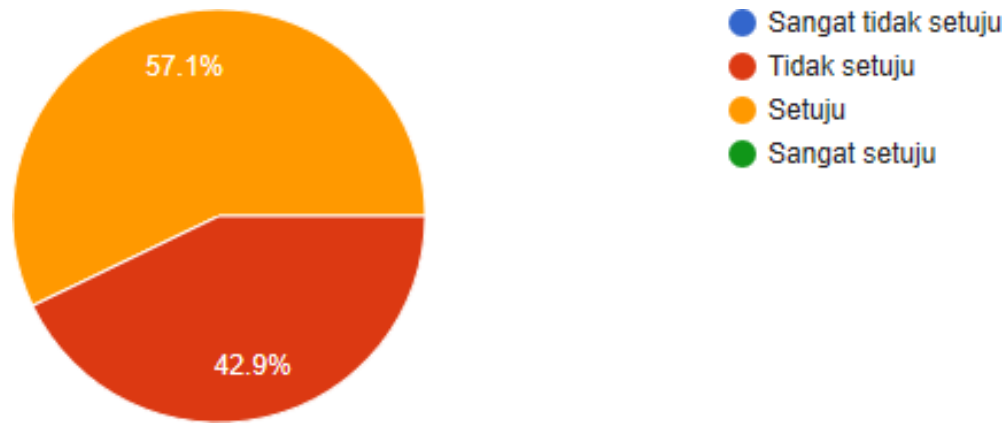

Sangat setuju

- Dosen dan mahasiswa Universitas Telkom bersikap ramah, cepat dan tanggap membantu selama kegiatan. 


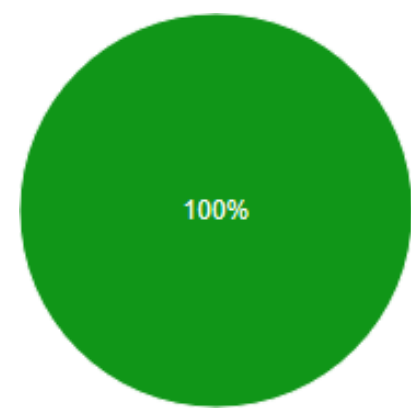

Sangat tidak setuju

Tidak setuju

Setuju

Sangat setuju

- Masyarakat setempat menerima dan mengharapkan program pengabdian masyarakat Universitas Telkom saat ini dan masa yang akan datang Masyarakat setempat menerima dan mengharapkan program pengabdian masyarakat Universitas Telkom saat ini dan masa yang akan datang.
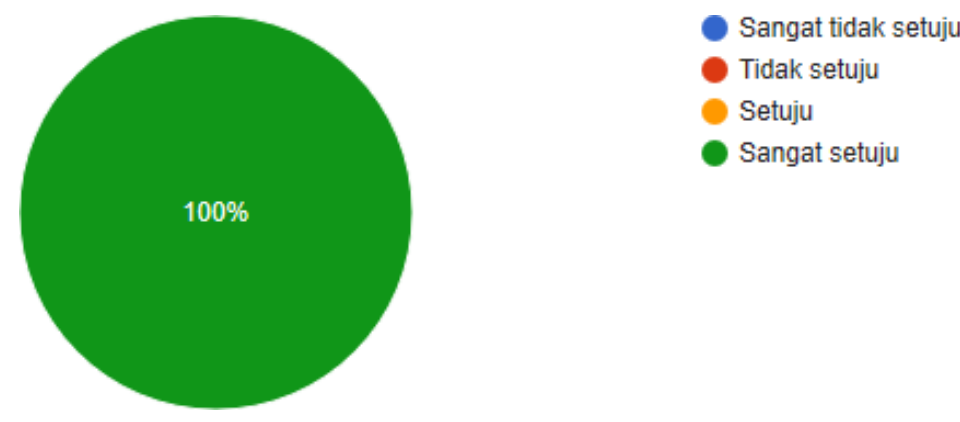

Berdasarkan hasil kuisioner di atas dapat simpulkan bahwa pengabdian masyarakat ini sudah sesuai dengan tujuan dan kebutuhan masyarakat sasar. Selain itu, masyarakat sasar mengharapkan program pengabdian masyarakat dari Universitas Telkom diadakan kembali pada masa yang akan datang. Akan tetapi, dari segi waktu pelaksanaan masyarakat sasar merasa tidak puas. Hal ini dikarenakan pelatihan hanya berlangsung selama 2.5 jam, yang mengakibatkan materi disampaikan secara terburu-buru. Masyarakat sasar berharap bisa dilaksanakan lebih dari sekali, sehingga mereka bisa mahir dalam membuat konten ajar interaktif berbasis multimedia.

Untuk mengukur apakah pelatihan ini memberikan pengaruh terhadap kemampuan peserta pelatihan dalam membuat materi ajar berbasis multimedia, kami melakukan observasi kemampuan sebelum dan sesudah pelatihan. Untuk melakukan observasi ini, kami memberikan 5 buah pertanyaan seputar pembuatan konten ajar menggunakan PowerPoint berbasis multimedia. Berikut ini adalah data hasil observasi kegiatan sebelum dan sesudah pelatihan. Nilai dari masingmasing peserta didapatkan dari 5 pertanyaan yang disesuaikan dengan materi pelatihan. 
Tabel 1. Nilai dari kemampuan membuat slide interaktif dengan PowerPoint berbasis multimedia sebelum dan setelah pelatihan.

\begin{tabular}{|c|c|c|c|c|c|c|c|}
\hline & \multicolumn{6}{|c|}{ Peserta Pengabdian kepada Masyarakat } \\
\hline & 1 & 2 & 3 & 4 & 5 & 6 & 7 \\
\hline $\begin{array}{c}\text { Sebelum } \\
\text { pelatihan }\end{array}$ & 30 & 0 & 0 & 10 & 20 & 0 & 0 \\
\hline $\begin{array}{c}\text { Setelah } \\
\text { pelatihan }\end{array}$ & 100 & 80 & 100 & 100 & 80 & 0 & 0 \\
\hline
\end{tabular}

Pada Tabel 1, terdapat 7 peserta yang akan dianalisis menggunakan $t$-test for difference between mean [6-8]. Klaim yang kita berikan pada kegiatan ini adalah adanya perbedaan yang signifikan pengetahuan mengenai pembuatan slide interaktif dengan PowerPoint berbasis multimedia setelah pelatihan dengan tingkat kepercayaan 95\%. Langkah pertama kita tentukan dahulu hipotesis dari masalah yang ingin kita uji.

$H_{0}: \mu_{d}=0$, (tidak adanya perbedaan)

$H_{1}: \mu_{d}>0$, (adanya perbedaan (klaim))

dengan $d$ adalah (nilai sebelum) - (nilai setelah) dan diketahui $\alpha=100-$ $95=5 \%$.

Selanjutnya adalah menentukan nilai t-test dengan langkah seperti ditunjukkan pada Tabel 2.

Tabel 2. Nilai t-test

\begin{tabular}{|c|c|c|c|c|c|c|c|}
\hline & 1 & 2 & 3 & 4 & 5 & 6 & 7 \\
\hline $\begin{array}{c}\text { Sebelum } \\
\text { pelatihan }\end{array}$ & 30 & 0 & 0 & 10 & 20 & 0 & 0 \\
\hline $\begin{array}{c}\text { Setelah } \\
\text { pelatihan }\end{array}$ & 100 & 80 & 100 & 100 & 80 & 100 & 100 \\
\hline$d$ & -70 & -80 & -100 & -90 & -60 & -100 & -100 \\
\hline$d^{2}$ & 4900 & 6400 & 10000 & 8100 & 3600 & 10000 & 10000 \\
\hline
\end{tabular}

dengan standardized test statistic adalah

$$
t=\frac{d-\mu_{d}}{s_{d} / \sqrt{n^{-}}}-14.013
$$

dan

$$
p-\text { value }=8 \times 10^{-6}
$$

Karena -value $=8 \times 10^{-6}<\alpha=0.05$, maka keputusannya adalah menolak $H_{0}$. Ini artinya, terdapat cukup bukti dengan tingkat kesalahan 5\% bahwa ada perubahan yang signifikan dalam pelatihan pembuatan slide interaktif dengan PowerPoint berbasis multimedia. 


\section{Kesimpulan}

Penerapan aplikasi pembelajaran interaktif berbasis multimedia untuk menunjang proses pelajar pengajar di SD Negeri Kertasari 01 Kabupaten Bandung telah berhasil dilakukan. Penerapan aplikasi pembelajaran ini dituangkan kedalam sebuah pelatihan pembuatan konten pembelajaran interaktif dengan multimedia. Masyarakat sasar yang dijadikan sebagai mitra adalah guru-guru SD Negeri Kertasari 01 Desa Tarumajaya Kecamatan Kertasari Kabupaten Bandung yang jaraknya sekitar $42 \mathrm{~km}$ dari Telkom University. Untuk mengukur apakah pelatihan ini memberikan pengaruh signifikan terhadap kemampuan peserta pelatihan dalam membuat materi ajar berbasis multimedia, kami telah melakukan observasi kemampuan peserta sebelum dan sesudah pelatihan. Hasil observasi telah dianalisis menggunakan t-test. Hasil dari analisis menunjukkan terdapat cukup bukti dengan tingkat kesalahan 5\% bahwa ada perubahan yang signifikan dalam pelatihan pembuatan konten pembelajaran interaktif berbasis multimedia.

\section{DAFTAR PUSTAKA}

[1]. Pawana, Made Giri, et al. "Pengembangan multimedia interaktif berbasis proyek dengan model ADDIE pada materi pemrograman web siswa kelas X semester genap di SMK Negeri 3 Singaraja." Jurnal Teknologi Pembelajaran Indonesia 6.1 (2016).

[2]. Fadlilah, Hervandha Ris Daniarti. "Pengembangan Media Pembelajaran PKn Berbasis Lectora Inspire Pada Siswa Kelas IV SD Negeri Pendulan Sumbersari Moyudan Sleman Tahun Ajaran 2015/2016." Universitas PGRI Yogyakarta (2015).

[3]. Bintoro, Henry Suryo. "Penerapan Interactive Multimedia Pada Pembelajaran Matematika Berbasis Kurikulum 2013." Prosiding Sendika" Peran Metamatika dan Pendidikan Matematia pada abad 21" 1.1 (2015).

[4]. Sukamto, Sukamto, and Asry Kusuma Wardani. "Pembelajaran matematika menggunakan cd interaktif amt berbasis lectora inspire untuk siswa SD." Mimbar Sekolah Dasar 3.1 (2016): 19-28.

[5]. Reni Nuraeni, dkk. , "Media kampanye pemeliharaan aliran sungai citarum di desa sukamukti kecamatan katapang Kabupaten Bandung", Charity Jurnal Pengabdian Masyarakat, Vol. 02 No. 01 (2019).

[6]. Utami, Retno Ritiasih, and Sartini Nuryoto. "Efektivitas pelatihan untuk meningkatkan keterampilan sosial pada anak sekolah dasar kelas 5." Indigenous: Jurnal Ilmiah Psikologi (2007).

[7]. Ibrahim, Doni Septumarsa, and Siti Partini Suardiman. "pengaruh penggunaan elearning terhadap motivasi dan prestasi belajar matematika siswa SD Negeri Tahunan Yogyakarta." Jurnal Prima Edukasia 2.1 (2014): 66-79.

[8]. Maryani, Maryani, and Christina Ismaniati. "Pengembangan Modul Penyusunan Rpp Tematik-integratif Berbasis Character Building Sebagai Bahan Belajar Guru SD." Jurnal Pendidikan Karakter 2 (2015). 